\title{
Exploration of the relationship between sleep position and isolated tongue base or multilevel surgery in obstructive sleep apnea
}

\author{
J. P. van Maanen • M. J. L. Ravesloot • \\ B. I. Witte $\cdot$ M. Grijseels $\cdot$ N. de Vries
}

Received: 24 January 2012 / Accepted: 6 March 2012 / Published online: 20 March 2012

(c) The Author(s) 2012. This article is published with open access at Springerlink.com

\begin{abstract}
This study aimed to elucidate the role of sleep position as a confounding factor on apnea hypopnea index (AHI) and surgical success in isolated tongue base or multilevel surgery. This study was conducted using retrospective analysis of patients who underwent hyoid suspension because of obstructive sleep apnea (OSA), in the St. Lucas Andreas Hospital, Amsterdam, The Netherlands, from 2004 to 2011. Concurrent surgical treatment was documented. Sleep positions and corresponding AHIs before and after surgery were compared. A total of 130 patients were included. 94 patients underwent surgery of base of tongue and palate (either uvulopalatopharyngoplasty or Z-palatoplasty), of whom 72 underwent concurrent radiofrequent thermotherapy of the base of tongue. 36 patients underwent base of tongue surgery alone, of whom 22 underwent concurrent radiofrequent thermotherapy of the base of tongue. 65 patients either had a successful reduction in AHI or in AI. Isolated tongue base or multilevel surgery was as successful on the supine AHI as it was on the AHI in other sleeping positions. Surgery was not more successful in the group with positiondependent patients as compared with the non-position-
\end{abstract}

J. P. van Maanen $(\varangle) \cdot$ M. J. L. Ravesloot · N. de Vries Department of Otolaryngology/Head Neck Surgery,

Sint Lucas Andreas Ziekenhuis, Jan Tooropstraat 164,

1061 AE Amsterdam, The Netherlands

e-mail: p.vanmaanen@slaz.nl

B. I. Witte

Department of Epidemiology and Biostatistics,

VU University Medical Centre, Amsterdam, The Netherlands

M. Grijseels

Department of Otolaryngology/Head Neck Surgery,

Leiden University Medical Centre, University of Amsterdam,

Amsterdam, The Netherlands dependent patients $(P=0.615)$. Successful and non-successful surgical results could not be explained by variations in percentages of supine sleep position. Sleep position is not a confounding factor on surgical outcomes in tongue base surgery. The results of isolated base of tongue or multilevel surgery in position-dependent OSA patients leave room for improvement, possibly through positional therapy.

Keywords Obstructive sleep apnea $\cdot$ Sleep surgery · Posture

\section{Introduction}

Obstructive sleep apnea (OSA) is the most prevalent sleepdisordered breathing problem, affecting 2-26\% of the general population, depending on gender, age and definition of the used criteria [1,2]. OSA is associated with significant morbidity, such as excessive daytime sleepiness, socially unacceptable snoring and impaired quality of life. Furthermore, if OSA remains untreated, patients are at higher risk of developing cardiovascular diseases [3, 4]. If the apnea-hypopnea index (AHI) is greater than 40 the risk of being involved in traffic accident increases [5, 6].

Bearing this in mind adequate treatment is of key importance. Conservative treatment of OSA consists of lifestyle alterations such as weight reduction, abstinence from alcohol and sedatives and avoidance of supine sleeping position, where appropriate. Continuous positive airway pressure (CPAP), introduced in 1981 by Sullivan, is in many countries regarded as the gold standard in treatment of OSA, with oral device therapy (mandibular reposition appliance, MRA) or surgery in reserve for CPAP failures [7]. Unfortunately CPAP compliance rates are 
often poor. Weaver and Grunstein report in their review that $29-83 \%$ of patients are non adherent and use their CPAP less than $4 \mathrm{~h}$ per night [8].

Since treatment remains indicated in patients with severe OSA with CPAP failure, treatment alternatives are being explored. A variety of site-specific surgical techniques have been developed. The traditional uvulopalatopharyngoplasty (UPPP) or Z-palatopharyngoplasty (ZPP) can be applied in patients with a palatal obstruction [9]. In patients with a base of tongue obstruction site, hyoidthyroidpexia (HTP), radiofrequent ablation of the base of tongue or genioglossus advancement (GA), for example, can be considered.

Traditionally, both subjective (Quality of life, Epworth Sleepiness Scales, etc.) and objective outcomes [polysomnography (PSG) variables] of surgical success are reported in literature.

Success rates of isolated tongue base surgery and of multilevel surgery have been extensively reported and vary between 45 and $62 \%$, depending on variables such as baseline AHI, BMI, level and configuration of obstruction and on the definition of success used [10-15].

Various PSG parameters such as the AHI or desaturation index (DI) are commonly reported, but rarely attention is paid to the distribution of the variables (AHI for example) in the four sleeping positions, namely the supine, left, right and prone sleep position.

An increasing amount of literature is being published on the role of sleep position in OSA [16-31]. Cartwright was the first to define the current positional OSA (POSA) criteria: an AHI in the worst sleeping position twice or more as compared with the AHI in the other positions [20]. In two studies from Israel and the Netherlands a remarkable steady $56 \%$ of patients have POSA [21, 23, 26]. An additional $30 \%$ of patients have a higher AHI in supine position than in the other positions, but not twice as high.

As early as 1978, Harper and Sauerland [32] suggested that when sleep apnea patients sleep in supine position, the tongue tends to fall backward against the pharyngeal wall, due to gravity. Our group recently reported that base of tongue obstruction or epiglottis obstruction, albeit not statistically significant, is associated with POSA [33].

We therefore question whether sleeping position may play a role in poorly understood successes and failures in sleep surgery, tongue base surgery in particular. We aimed to elucidate the role of sleep position as a confounding factor on $\mathrm{AHI}$ and surgical success in tongue base surgery [34].

The aims of this study were to resolve the following:

1. Are unexplained positive or negative outcomes related to variations in percentages of supine sleep position?
2. What is the effect of tongue base surgery on the AHI in supine position in comparison to other sleep positions?

3. Is positional OSA a predictor of surgical outcome?

\section{Materials and methods}

\section{Patients}

We retrospectively reviewed our institutional database of patients diagnosed with OSA and treated with sleep surgery in our hospital from 2004 to 2011. The diagnostic work-up consisted of patient history, physical examination, a full overnight PSG and midazolam or propofol-induced sleep endoscopy to evaluate the site(s) of obstruction and further treatment. In this period (2004-2011) patients were operated on by different surgeons, but all surgical procedures were supervised by one and the same surgeon and thus performed the same way. Patients with moderate to severe OSA and both retrolingual and retropalatal collapse and refusal or non-acceptance of NCPAP treatment were offered multilevel surgical treatment.

In this study we retrospectively included patients with moderate to severe OSA who had undergone a hyoid suspension [35] with or without additional surgical treatment: an uvulopalatopharyngoplasty according to Fujita [36] (in patients with tonsils) or Z-palatoplasty according to Friedman [37] in patients without tonsils and radiofrequent ablation of the base of tongue (RFTB) [38].

\section{Polysomnography}

Polysomnogram recordings were carried out using a digital polygraph system (Embla A10, Broomfield, USA), which recorded the electroencephalogram (FP2-C4/C4-O2), electrooculogram, EKG and submental and anterior tibial electromyogram. Nasal airflow was measured by a pressure sensor and arterial oxygen saturation by finger pulse oximetry. Thoraco-abdominal motion was recorded by straps containing piezoelectric transducers. Snoring was recorded through a piezo snoring sensor. Body position was determined by a position sensor (Sleepsense, St. Charles, USA), which was attached to the midline of the abdominal wall. This sensor differentiated between the upright, left side, right side, prone and supine position. All signals were recorded with DDD (digital sampling, digital filtering, digital storage) recording technology, permitting a sample efficiency of $90 \%$ and a sample rate up to $200 \mathrm{~Hz}$. Storage was done on a PCMCIA flash-card. Data were downloaded to the computer and analyzed by dedicated sleep software (Somnologica, Broomfield, USA) and manually reviewed for analysis by an experienced sleep investigator. 


\section{Definitions}

The recommended diagnostic criteria for obstructive sleep apnea syndrome included an apnea hypopnea index (AHI) of five or more and evidence of daytime sleepiness. The AHI was defined as the mean number of apneas and hypopneas per hour during sleep and apnea as a period of $10 \mathrm{~s}$ or more with a reduction of oronasal airflow of $>90 \%$. A hypopnea was defined as an episode of more than $30 \%$ airflow reduction of the baseline (calculated from the preceding period of $100 \mathrm{~s}$ ) during at least $10 \mathrm{~s}$. As per the AASM guidelines AHI thresholds were 5, 15 and 30 events per hour for mild, moderate and severe levels of OSA, respectively [39]. Desaturation index was defined as the number of desaturations $\geq 4 \%$ for a minimum of $10 \mathrm{~s}$ per hour of sleep. Full overnight PSG was repeated 3-4 months postoperatively. Surgical success was defined according to Sher's criteria: AHI reduction of at least $50 \%$ and $\mathrm{AHI}$ reduction to below 20 [40]. When using the AI as an outcome measure the following criteria were applied to define success: reduction by at least $50 \%$ and below a value of 10 .

\section{Statistics}

Changes in parameters before and after treatment were tested with a paired Wilcoxon signed rank test. Differences between groups were tested with a $\chi^{2}$-test in case of categorical variables and with a Wilcoxon rank sum test in case of continuous variables. The influence of treatment on POSA was tested with the McNemar test for matched pairs. Exact $95 \%$ confidence intervals were calculated for the success proportions and the (overall) response rates. All statistical analyses were performed with SPSS (version 15.0). A $P$ value $<0.05$ was considered to be significant.

\section{Results}

We included 130 patients; patient characteristics are shown in Table 1.94 patients underwent a combined procedure of base of tongue and palate, from which 72 underwent concurrent radiofrequent thermotherapy of the base of tongue (RFTB). 36 Patients underwent base of tongue surgery alone (HTP), from which 22 underwent concurrent RFTB.

No significant differences in AHI, supine AHI, nonsupine AHI, percentage of supine sleep position, total sleep time, arousal index and awakenings were found between the different surgical groups when divided into solely base of tongue surgery (HTP either with or without concurrent RFTB) and combined base of tongue and palate surgery (with either UPPP or ZPP) (Table 2).

The mean AHI of all 130 patients decreased significantly from 36.7 (range $9.0-100.9)$ to $25.1(P<0.001)$.
Table 1 Baseline characteristics

\begin{tabular}{ll}
\hline Variable & Mean \pm SD \\
\hline Age (year) & $49.9 \pm 9.7$ \\
BMI $\left(\mathrm{kg} / \mathrm{m}^{2}\right)$ & $27.3 \pm 2.8$ \\
AHI $(/ \mathrm{h})$ & $36.7 \pm 14.4$ \\
AHI supine $(/ \mathrm{h})$ & $51.2 \pm 24.8$ \\
AHI supine $(\%)$ & $37.4 \pm 24.7$ \\
Ratio (male:female) & $9: 1$
\end{tabular}

AHI in supine position decreased significantly from 51.2 to $39.3(P<0.001)$. AHI in left position decreased significantly from 23.7 to $11.2(P<0.001)$. AHI in right position decreased significantly from 21.1 to $14.2(P<0.001)$. AHI in prone position decreased significantly from 11.2 to 6.4 $(P<0.001)$.

A successful reduction in AHI, according to Sher's critera was seen in 49 patients (CI 29.3-46.6\%) and in AI in 54 patients (CI 33.2-50.9\%). Half of the patients (CI 41.1-58.9\%) either had a successful reduction in AHI or in AI.

In general, patients who had a successful reduction in AHI slept less often in supine position after treatment than before treatment compared with the patients who did not have a successful reduction in AHI $(P=0.024)$. The difference between the percentage of total sleep time (TST) in supine position before and after surgery was not significant within each group ( $P=0.126$ and 0.124 for both groups, respectively). The mean difference in AHI before and after treatment was $26.3 / \mathrm{h}$ in the group of patients with a successful reduction in AHI, which is significantly higher than the mean difference in the other group $(P<0.001)$. The mean AHI in supine position decreased by $30.2 / \mathrm{h}$ in the first group, again significantly higher than the difference in the other group $(P<0.001)$. The differences in AHI, AHI in supine position and AHI in non-supine position before and after treatment were all significant for the patients with successful AHI reduction (all $P<0.001$ ), and not for the patients in the non-successful group $(P=0.099$ total AHI, $P=0.749$ AHI supine, $P=0.052$ AHI non supine). The AHI in left or right position decreased significantly for the successful group, whereas AHI in prone position did not. In the unsuccessfully treated group, the AHI in prone and left position did decrease significantly after surgery (Table 2). Total sleep time, arousal index and number of awakenings did not change significantly after surgery (data not shown here).

Seventy patients suffered from POSA pre-operatively. Within this group the total AHI decreased significantly from 32.7 to $23.7(P<0.001)$, and the AHI in supine position decreased significantly from 57.9 to 42.2 $(P<0.001)$. The percentage of patients that slept in supine position did not change significantly after treatment $(P=0.654)$. In 34 of the 70 position-dependent patients 
Table 2 Mean values of AHI and AHI in different positions, before and after surgery for different groups of patients

\begin{tabular}{|c|c|c|c|c|c|c|c|}
\hline & Mean (before) & Mean (after) & $P$ value (within) & Mean (before) & Mean (after) & $P$ value (within) & $P$ value (between) \\
\hline AHI successful ${ }^{\mathrm{a}}$ & \multicolumn{3}{|l|}{ Yes $(n=49)$} & \multicolumn{4}{|l|}{ No $(n=81)$} \\
\hline AHI & 35.8 & 9.5 & $<0.001$ & 37.2 & 34.5 & 0.099 & $<0.001$ \\
\hline AHI supine & 49.1 & 18.9 & $<0.001$ & 52.5 & 51.6 & 0.749 & $<0.001$ \\
\hline AHI non supine & 23.1 & 5.1 & $<0.001$ & 27.7 & 23.9 & 0.052 & $<0.001$ \\
\hline AHI prone & 4.9 & 3.5 & 0.647 & 15.0 & 8.1 & $\mathbf{0 . 0 3 3}$ & 0.234 \\
\hline AHI left & 18.7 & 4.9 & $<0.001$ & 26.8 & 20.3 & 0.004 & 0.077 \\
\hline AHI right & 15.9 & 4.8 & $<0.001$ & 24.2 & 19.9 & 0.137 & 0.061 \\
\hline$\%$ supine sleep position & 42.8 & 36.9 & 0.126 & 34.2 & 37.9 & 0.124 & 0.024 \\
\hline AI successful ${ }^{\mathrm{b}}$ & \multicolumn{3}{|l|}{ Yes $(n=54)$} & \multicolumn{4}{|l|}{ No $(n=76)$} \\
\hline AI & 20.0 & 2.7 & $<0.001$ & 21.0 & 21.9 & 0.376 & $<0.001$ \\
\hline AHI & 34.4 & 13.1 & $<0.001$ & 38.3 & 33.9 & 0.026 & $<0.001$ \\
\hline AHI supine & 51.8 & 24.1 & $<0.001$ & 51.5 & 50.5 & 0.792 & $<0.001$ \\
\hline AHI non supine & 22.7 & 8.7 & $<0.001$ & 28.2 & 22.8 & 0.011 & 0.003 \\
\hline AHI prone & 10.4 & 3.4 & 0.154 & 11.9 & 8.5 & 0.161 & 0.922 \\
\hline AHI left & 21.9 & 8.3 & $<0.001$ & 25.4 & 19.1 & 0.006 & 0.029 \\
\hline AHI right & 18.5 & 7.5 & 0.001 & 23.3 & 19.2 & 0.098 & 0.141 \\
\hline$\%$ supine sleep position & 36.8 & 37.7 & 0.679 & 38.4 & 37.7 & 0.886 & 0.720 \\
\hline AHI or AI successful & \multicolumn{3}{|l|}{ Yes $(n=65)$} & \multicolumn{4}{|l|}{ No $(n=65)$} \\
\hline AHI & 34.8 & 13.1 & $<0.001$ & 38.5 & 37.1 & 0.501 & $<0.001$ \\
\hline AHI supine & 49.8 & 23.8 & $<0.001$ & 52.7 & 54.8 & 0.498 & $<0.001$ \\
\hline AHI non supine & 23.6 & 8.4 & $<0.001$ & 28.3 & 25.2 & 0.152 & $<0.001$ \\
\hline AHI prone & 9.4 & 3.5 & 0.115 & 12.9 & 9.2 & 0.197 & 0.808 \\
\hline AHI left & 20.8 & 8.2 & $<0.001$ & 26.7 & 20.9 & 0.023 & 0.027 \\
\hline AHI right & 18.0 & 6.9 & $<0.001$ & 24.2 & 21.4 & 0.258 & 0.071 \\
\hline$\%$ supine sleep position & 38.2 & 37.2 & 0.838 & 36.7 & 37.9 & 0.575 & 0.565 \\
\hline Positional OSA ${ }^{c}$ & \multicolumn{3}{|l|}{ Yes $(n=70)$} & \multicolumn{4}{|l|}{ No $(n=60)$} \\
\hline AHI & 32.7 & 23.7 & $<0.001$ & 41.3 & 26.6 & $<0.001$ & 0.044 \\
\hline AHI supine & 57.9 & 42.2 & $<0.001$ & 43.5 & 35.6 & 0.132 & 0.107 \\
\hline AHI non supine & 14.9 & 13.3 & 0.106 & 38.8 & 20.8 & $<0.001$ & $<0.001$ \\
\hline AHI prone & 4.4 & 6.3 & 0.793 & 19.1 & 6.4 & 0.002 & 0.039 \\
\hline AHI left & 16.0 & 11.6 & 0.159 & 32.8 & 17.9 & $<0.001$ & $<0.001$ \\
\hline AHI right & 12.8 & 13.0 & 0.501 & 30.8 & 15.6 & $<0.001$ & 0.001 \\
\hline$\%$ supine sleep position & 43.9 & 43.9 & 0.654 & 29.9 & 30.1 & 0.853 & 0.642 \\
\hline Treatment & \multicolumn{3}{|c|}{$\mathrm{HTP} / \mathrm{HTP}+\mathrm{RFTB}(n=36)$} & \multicolumn{4}{|c|}{$\mathrm{HTP}+\mathrm{UPPP} / \mathrm{ZPP}(n=94)$} \\
\hline AHI & 26.7 & 16.4 & $<0.001$ & 38.4 & 26.5 & $<0.001$ & 0.744 \\
\hline AHI supine & 41.4 & 30.4 & 0.059 & 52.9 & 40.7 & $<0.001$ & 0.837 \\
\hline AHI non supine & 19.8 & 8.5 & 0.001 & 27.0 & 18.2 & $<0.001$ & 0.676 \\
\hline AHI prone & 9.6 & 0.5 & 0.043 & 11.4 & 7.4 & 0.133 & 0.275 \\
\hline AHI left & 15.5 & 10.8 & 0.055 & 25.2 & 15.2 & $<0.001$ & 0.474 \\
\hline AHI right & 19.0 & 8.5 & 0.010 & 21.5 & 15.1 & 0.008 & 0.365 \\
\hline$\%$ supine sleep position & 34.2 & 42.1 & 0.260 & 38.0 & 36.8 & 0.750 & 0.162 \\
\hline
\end{tabular}

Boldfaced values are the significant differences before and after treatment within the groups or between the groups

${ }^{\text {a }}$ Reduction in $\mathrm{AHI}$ of at least $50 \%$ and to below 20

${ }^{\mathrm{b}}$ Reduction in $\mathrm{AI}$ of at least $50 \%$ and to below 10

c AHI supine/AHI non supine $>2$

the treatment was successful (CI 36.4-60.1\%) (Table 3). The other 60 pre-operative non-POSA patients had a significantly lower AHI following surgery $(P<0.001)$. A significant decrease of the AHI was seen in all positions except the AHI in supine position. The difference in supine AHI before and after treatment between the POSA and 
Table 3 Success rates split for different outcomes of positional OSA

\begin{tabular}{llllr}
\hline & Percentage & $95 \%$ CI & Percentage & $95 \%$ CI \\
\hline Positional OSA $^{\text {a }}$ & Yes $(n=70)$ & & No $(n=60)$ & \\
AHI successful & 35.7 & $24.6-48.1$ & 40.0 & $27.6-53.5$ \\
AI successful & 42.9 & $31.1-55.3$ & 40.7 & $28.1-54.3$ \\
AHI or AI successful & 48.6 & $36.4-60.1$ & 51.7 & $38.4-64.7$ \\
\hline
\end{tabular}

The $P$ values denote the difference in these rates between the two groups

${ }^{\text {a }}$ AHI supine/AHI non supine $>2$

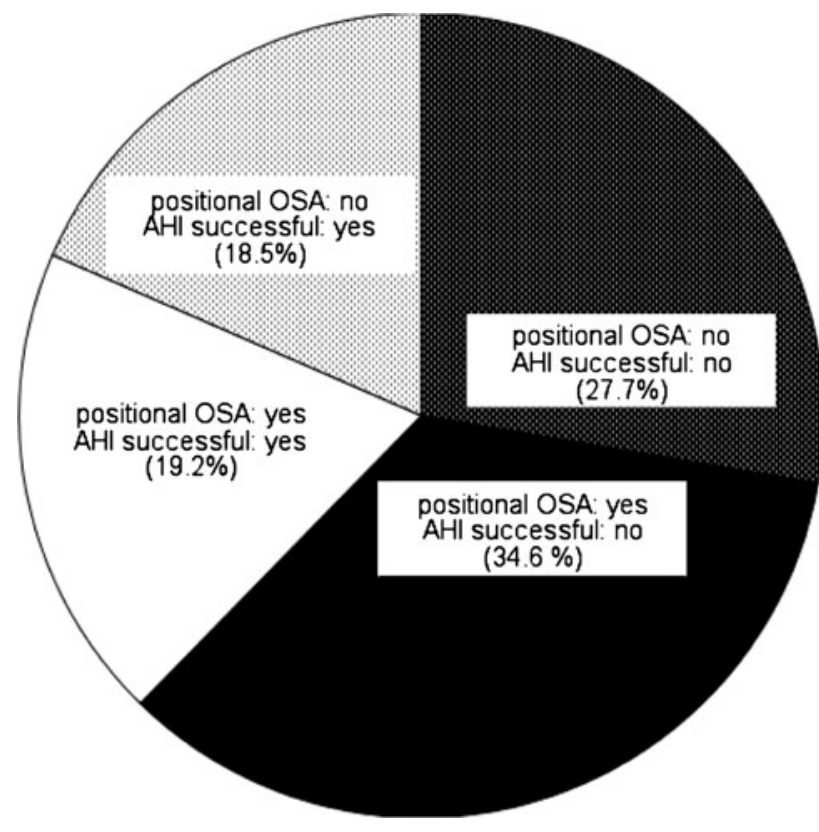

Fig. 1 Distribution of surgical success amongst POSA and nonPOSA patients

Table 4 Effect of surgery on position-dependency

\begin{tabular}{|c|c|c|c|c|c|c|}
\hline & \multirow[t]{3}{*}{ Positional $\mathrm{OSA}^{\mathrm{a}}$} & \multicolumn{4}{|c|}{ Post treatment } & \multirow[t]{3}{*}{$P$ value } \\
\hline & & \multicolumn{2}{|c|}{ No } & \multicolumn{2}{|c|}{ Yes } & \\
\hline & & $n$ & $\%$ & $n$ & $\%$ & \\
\hline \multirow[t]{2}{*}{ Pre treatment } & No & 34 & 57.6 & 25 & 42.4 & \multirow[t]{2}{*}{0.451} \\
\hline & Yes & 19 & 27.1 & 51 & 72.9 & \\
\hline
\end{tabular}

${ }^{a}$ AHI supine/AHI non supine $>2$

non-POSA groups was not significant $(P=0.107)$, while the AHI decreased more for the non-POSA patients $(P=0.044)$ (Table 2). Furthermore, in the non-POSA patients the post-operative decrease in non-supine, prone, left and right AHI was significant when compared with these parameters in the POSA patients $(P<0.001$, $P=0.039, P<0.001, P=0.001)$.

Surgery was not more successful in the group with position-dependent patients than in the other group $(P=0.615)$ (Fig. 1). Most positional patients remained positional after surgery and most non-positional patients remained nonpositional (72.9 and 57.6 \%, $P=0.451$ ) (Table 4).

\section{Discussion}

The present study is the first which looks into the relation between tongue base surgery either with or without concurrent palate surgery and sleep position.

Our study population did not solely consist of isolated base of tongue surgery patients but also included patients who concurrently underwent palate surgery. Ideally we would have studied isolated base of tongue surgery. But most patients we diagnostically worked up for HTP suffered from multilevel obstruction. Although we compared the isolated base of tongue surgery group with the combined base of tongue and palate surgery group and found no significant differences between the groups, this is a limitation of our study.

To our best knowledge only three earlier studies have been published on the effect of sleep position on outcomes of palate surgery (UPPP) [34, 41, 43]. So far, no papers have been published on the combination approach of sleep surgery and positional therapy (PT).

The overall success rate and overall response rate of this series of HTP/tongue base surgery with or without concomitant palatal surgery in patients with moderate to severe OSA and CPAP failure are 38 and $60 \%$, respectively, which is in the low-normal range compared with previously reported series [10-15]. Improvement of treatment outcome is mandatory if treatment intent is "salvage" in CPAP failures.

It is a clinical reality in sleep surgery that remarkable differences in outcome can occur amongst patients with comparable pre-operative AHI, BMI, clinical findings such as tongue size, tonsil size and drug-induced sleep endoscopy (DISE) findings [33, 43]. We took a closer look to evaluate whether discrepancies between expected and actual outcome could be explained by changes in body position before and after treatment. For this reason the patients in the present series were divided into positional and non-positional groups. 
In general, in both positional and non-positional patients, the percentage supine sleep position remained remarkably constant after surgery and remarkable successes or failures could not be explained by considerable changes in percentage supine position. In conclusion, surgery did not influence patient's position-dependency (Table 4).

Hyoid suspension is traditionally thought to exert its effect by increasing the retrolingual airway space. We hypothesised therefore that in successful surgery, more outspoken decreases in AHI would be found in the supine position, than in other sleep positions.

Our results show that HTP did not have better effect on the supine $\mathrm{AHI}$ in comparison with the AHI in other sleeping position components. When surgery was either successful or non-successful, the reduction in AHI was uniform in all sleeping positions.

Earlier Stuck et al. reported that MRI studies do not show enlargement of the retrolingual airway space following HTP. These authors concluded that the effect of HTP was in increased general stabilization of the upper airway, not an enlargement of the retrolingual airway [44]. Our present findings provide further support for this concept. However, our follow-up was relatively short (3-4 months). Further research, to evaluate long term results is ongoing.

POSA occurs in $56 \%$ [26] of OSA patients. PT as treatment for POSA is gaining momentum [30]. After surgical failure in positional patients, a further decrease of the AHI can theoretically be accomplished by prevention of the supine sleep position. This leads to the concept of multimodality treatment. Theoretically, in POSA, multilevel surgery with PT would achieve better results than surgery or PT alone. This is in concordance with earlier research papers in palate surgery. Katsantonis et al. [41] studied the effect of UPPP on sleep posture and differences in uvulopalatopharyngoplasty (UPPP) results in various sleep positions in a small series of 17 patients. They found that following UPPP, the AHI significantly improved in the lateral position. They also found that during sleep in a supine position, the AHI did not show significant improvement. They conclude that UPPP enhances the position effect on OSA because it readily eliminates obstructive events in the lateral sleep position. In other words, the difference in AHI in supine and non-supine positions are more pronounced postoperatively. They are of opinion that additional positional therapy could significantly improve response to treatment with UPPP. Lee et al. [34] studied the effect of sleep position on surgical outcomes as well. They studied 69 consecutive patients who underwent a UPPP. After categorizing the patients into four groups according to the change in AHI after surgery, they found that the failure group had a higher proportion of supine position dependency than any other group. In a second paper published by the same group, results show that UPPP is a successful treatment for obstructive events occurring in the lateral sleep position, especially in patients without positional dependency [42]. A suggestion is made that patients who have become position-dependent may benefit from positional therapy after UPPP.

Until recently, PT consisted of the "tennis ball technique". A variety of tennis balls, squash balls, shark fins, special pajamas and vests all had the same concept of a bulky mass worn on the back. All these devices have in common that they are not comfortable, disrupt sleep architecture and the long-term compliance is a disappointing $10 \%$ [45]. A recent paper by our group for the first time showed that a small buzzing device worn in the neck can prevent supine sleeping position without disrupting sleep [30].

\section{Conclusion}

The difference between the percentage of total sleep time in supine position before and after surgery was not significant. The differences in AHI, AHI in supine position and $\mathrm{AHI}$ in non-supine position before and after treatment were all significant for the patients with successful AHI reduction (all $P<0.001$ ), and not for those patients in the non-successful group $(P=0.099$ total AHI, $P=0.749$ AHI supine, $P=0.052$ AHI non supine).

Isolated tongue base or multilevel surgery was as successful on the supine AHI as it was on the AHI in other sleeping positions.

Surgery was not more successful in the group with position-dependent patients as compared with the nonposition-dependent patients $(P=0.615)$. Successful and non-successful surgical results could not be explained by variations in percentages of supine sleep position.

Surgery was not more successful in the group with position-dependent patients than in the non-positiondependent group $(P=0.615)$.

From this retrospective analysis we conclude that sleep position is not a confounding factor on surgical outcomes in tongue base surgery.

The results of base of tongue or multilevel surgery in position-dependent OSA patients leave room for improvement, possibly through positional therapy. Further research on the combined effect of multilevel surgery and positional therapy is ongoing.

Acknowledgments We wish to acknowledge the help and guidance provided by C. Knegt, resident Otolaryngology/Head Neck Surgery, University Medical Centre, Utrecht, The Netherlands.

Conflict of interest None of the authors have financial or other relationship that might lead to a conflict of interest. 
Open Access This article is distributed under the terms of the Creative Commons Attribution License which permits any use, distribution, and reproduction in any medium, provided the original author(s) and the source are credited.

\section{References}

1. Kryger MH (2000) Diagnosis and management of sleep apnea syndrome. Clin Cornerstone 2:39-47

2. Young T, Hutton R, Finn L, Baddr S, Palta M (1996) The gender basis in sleep apnea diagnosis: are women missed because they have different symptoms? Arch Intern Med 156:2445-2451

3. Young T, Finn L, Peppard PE et al (2008) Sleep disordered breathing and mortality: eighteen-year follow-up of the Wisconsin sleep cohort. Sleep 31:1071-1078

4. Redline S, Yenokyan G, Gottlieb DJ et al (2010) Obstructive sleep apnea-hypopnea and incident stroke: the sleep heart health study. Am J Respir Crit Care Med 182:269-277

5. Findley LJ, Weiss JW, Jabour ER (1991) Drivers with untreated sleep apnea. A cause of death and serious injury. Arch Intern Med 151:1451-1452

6. Smolensky MH, Di Milia L, Ohayon MM, Philip P (2011) Sleep disorders, medical conditions, and road accident risk. Accid Anal Prev 43:533-548

7. Randerath WJ, Verbraecken J, Andreas S et al (2011) European Respiratory Society task force on non-CPAP therapies in sleep apnoea. Non-CPAP therapies in obstructive sleep apnoea. Eur Respir J 37:1000-1028

8. Weaver TE, Grunstein RR (2008) Adherence to continuous positive airway pressure therapy: the challenge to effective treatment. Proc Am Thorac Soc 5:173-178

9. Woodson BT (2008) Structural effectiveness of pharyngeal sleep apnea surgery. Sleep Med Rev 12:463-479

10. Kezirian EJ, Goldberg AN (2006) Hypopharyngeal surgery in obstructive sleep apnea: an evidence-based medicine review. Arch Otolaryngol Head Neck Surg 132:206-213

11. Baisch A, Maurer JT, Hörmann K (2006) The effect of hyoid suspension in a multilevel surgery concept for obstructive sleep apnea. Otolaryngol Head Neck Surg 134:856-861

12. Richard W, Kox D, den Herder C, van Tinteren H, de Vries N (2007) One stage multilevel surgery (uvulopalatopharyngoplasty, hyoid suspension, radiofrequent ablation of the tongue base with/ without genioglossus advancement), in obstructive sleep apnea syndrome. Eur Arch Otorhinolaryngol 264:439-444

13. Benazzo M, Pagella F, Matti E et al (2008) Hyoidthyroidpexia as a treatment in multilevel surgery for obstructive sleep apnea. Acta Otolaryngol 128:680-684

14. Van den Broek E, Richard W, van Tinteren H, de Vries N (2008) UPPP combined with radiofrequency thermotherapy of the tongue base for the treatment of obstructive sleep apnea syndrome. Eur Arch Otorhinolaryngol 265:1361-1365

15. Yi HL, Sun XQ, Chen B et al (2011) Z-palatopharyngoplasty plus genioglossus advancement and hyoid suspension for obstructive sleep apnea hypopnea syndrome. Otolaryngol Head Neck Surg 144:469-473

16. Kavey NB, Blitzer A, Gidro-Frank S, Korstanje K (1985) Sleeping position and sleep apnea syndrome. Am J Otolaryngol 6:373-377

17. Cartwright RD (1984) Effect of sleep position on sleep apnea severity. Sleep 7:110-114

18. Chaudhary BA, Chaudhary TK, Kolbeck RC, Harmon JD, Speir WA (1986) Therapeutic effect of posture in sleep apnea. South Med J 79:1061-1062
19. George CF, Millar TW, Kryger MH (1988) Sleep apnea and body position during sleep. Sleep 11:90-99

20. Cartwright RD, Diaz F, Lloyd S (1991) The effect of sleep posture and sleep stage on apnea frequency. Sleep $14: 351-353$

21. Oksenberg A, Silverberg DS, Arons E, Radwan H (1997) Positional vs nonpositional obstructive sleep apnea patients. Chest 112:629-639

22. Itasaka Y, Miyazaki S, Ishikawa K, Togawa K (2000) The influence of sleep position and obesity on sleep apnea. Psychiatry Clin Neurosci 54:340-341

23. Oksenberg A, Khamaysi I, Silverberg DS, Tarasiuk A (2000) Association of body position with severity of apneic events in patients with severe nonpositional obstructive sleep apnea. Chest 118:1018-1024

24. Akita Y, Kawakatsu K, Hattori C, Hattori H, Suzuki K, Nishimura T (2003) Posture of patients with sleep apnea during sleep. Acta Otolaryngol Suppl 550:41-45

25. Mador MJ, Kufel TJ, Magalang UJ, Rajesh SK, Watwe V, Grant BJ (2005) Prevalence of positional sleep apnea in patients undergoing polysomnography. Chest 128:2130-2137

26. Richard W, Kox D, den Herder C, Laman M, van Tinteren H, de Vries N (2006) The role of sleeping position in obstructive sleep apnea. Eur Arch Otorhinolaryngol 263:946-950

27. Permut I, Diaz-Abad M, Chatila W, Crocetti J, Gaughan JP, D' Alonzo GE, Krachman SL (2010) Comparison of positional therapy to CPAP in patients with positional obstructive sleep apnea. J Clin Sleep Med 6:238-243

28. van Kesteren ER, van Maanen JP, Hilgevoord AA, Laman DM, de Vries N (2011) Quantitative effects of trunk and head position on the apnea hypopnea index in obstructive sleep apnea. Sleep 34:1075-1081

29. Schwab RJ (2011) A quantum advance in PSG recordings: the importance of head position in mediating the AHI. Sleep 34:985-986

30. van Maanen JP, Richard W, van Kesteren ER, Ravesloot MJL, Laman DM, Hilgevoord AAJ, de Vries N (2011) Evaluation of a new simple treatment for positional sleep apnea patients. J Sleep Res [Epub ahead of print]

31. Ravesloot MJL, Frank MH, Van Maanen JP, Dun L, Verhagen E, de Lange J, de Vries N. Positional OSA (2012) How often is it clinical relevant and how often is treatment indicated. A proposal for a new classification system, based on its clinical significance (submitted)

32. Harper R, Sauerland E (1978) The role of the tongue in sleep apnea. In: Guilleminault C, Dement W (eds) Sleep apnea syndromes. pp 219-34

33. Ravesloot MJL, de Vries N (2011) 100 consecutive patients undergoing drug-induced sleep endoscopy-results and evaluation. Laryngoscope 121:2710-2716

34. Lee CH, Shin HW, Han DH et al (2009) The implication of sleep position in the evaluation of surgical outcomes in obstructive sleep apnea. Otol Head Neck Surg 140:531-535

35. Riley RW, Powell NB, Guilleminault C (1994) Obstructive sleep apnea and the hyoid: a revised surgical procedure. Otolaryngol Head Neck Surg 111:717-721

36. Fujita S, Conway W, Zorick F, Roth T (1981) Surgical corrections of anatomical abnormalities in obstructive sleep apnea syndrome: uvulopalatopharyngoplasty. Otolaryngol Head Neck Surg 89:923-934

37. Friedman M, Ibrahim HZ, Vidyasagar R, Pomeranz J, Joseph NJ (2004) Z-palatoplasty (ZPP): a technique for patients without tonsils. Otolaryngol Head Neck Surg 131:89-100

38. Stuck BA, Köpke J, Maurer JT et al (2003) Lesion formation in radiofrequency surgery of the tongue base. Laryngoscope 113:1572-1576 
39. (1999) Sleep-related breathing disorders in adults: recommendations for syndrome definition and measurement techniques in clinical research. The Report of an American Academy of Sleep Medicine Task Force. Sleep 22:667-89

40. Sher AE, Schechtman KB, Piccirillo JF (1996) The efficacy of surgical modifications of the upper airway in adults with obstructive sleep apnea syndrome. Sleep 19:156-177

41. Katsantonis GP, Miyazaki S, Walsh J (1990) Effects of uvulopalatopharyngoplasty on sleep architecture and patterns of obstructed breathing. Laryngoscope 10:1068-1072

42. Lee CH, Kim SW, Han K et al (2011) Effect of uvulopalatopharyngoplasty on positional dependency in obstructive sleep apnea. Arch Otolaryngol Head Neck Surg 137:675-679
43. Kezirian EJ, Hohenhorst W, de Vries N (2011) Drug-induced sleep endoscopy: the VOTE classification. Eur Arch Otorhinolaryngol 268:1233-1236

44. Stuck BA, Neff W, Hörmann K et al (2005) Anatomic changes after hyoid suspension for obstructive sleep apnea: an MRI study. Otolaryngol Head Neck Surg 133:397-402

45. Oksenberg A, Silverberg D, Offenbach D, Arons E (2006) Positional therapy for obstructive sleep apnea patients: a 6-month follow-up study. Laryngoscope 116:1995-2000 